\title{
A formação dos formadores: um estudo sobre o PNAIC*
}

\author{
The formation of educators: \\ a study on PNAIC
}

\section{La formación de formadores: los estudios sobre del PNAIC}

\author{
Maria Elizabete Souza Couto ${ }^{* *}$ \\ Alba Lúcia Gonçalves ${ }^{* * *}$
}

\begin{abstract}
Resumo: Este artigo tem como objetivo analisar o processo de formação de professores formadores (Orientadores de Estudos - OE) que assumem a responsabilidade da formação dos professores alfabetizadores e como esses formadores constroem conhecimento para contribuir na formação dos professores alfabetizadores. A pesquisa é de natureza qualitativa e, para coleta de dados, utilizamos um questionário que foi respondido por 49 professores formadores. Na leitura dos dados, compreendemos que a formação dos formadores é um campo ainda pouco estudado e explorado. Os formadores relataram a construção e a mobilização de uma base de conhecimento necessária ao desenvolvimento dessa função e, consequentemente, a construção do seu processo formador para formar os professores alfabetizadores, (re)constituindo situações que são teóricas e práticas, mobilizando conhecimentos referentes, por exemplo, ao planejamento, à leitura, à escrita, à oralidade. Assim, os formadores estão ampliando seu repertório de conhecimentos e ajudando os professores alfabetizadores a construir conhecimentos na área de alfabetização.
\end{abstract}

Palavras-chave: Formação de Formadores. Professor Alfabetizador. PNAIC.

\begin{abstract}
This paper has the aim to analyze the process of the formation of educator teachers (Study advisors) that assume the responsibility of the literacy teachers' education and how they build knowledge to contribute in the education of literacy teachers. The research is of qualitative nature and for data collection we used a questionnaire that was answered by 49 educator teachers. When analyzing data, we understood that the formation of educators is still a little studied and explored field. The educators pointed out the construction and the mobilization of a necessary knowledge base to develop

\footnotetext{
* Este artigo, em sua versão inicial, foi apresentado no II Congresso Nacional de Formação de Professores e XII Congresso Estadual Paulista sobre Formação de Educadores, realizado em Águas de Lindoia (SP), de 7 a 9 de abril de 2014 .

** Professora da Universidade Estadual de Santa Cruz (UESC). E-mail: <melizabetesc@gmail.com>

*** Professora da Universidade Estadual de Santa Cruz (UESC). E-mail: <albauesc@yahoo.com.br>
} 
the area and, consequently, the construction of the educating process to educate literacy teachers, (re)constituting situations that are theoretical and practical, mobilizing knowledge that refer, for instance, to planning, reading, writing, speaking. Thus, the educators are enlarging their knowledge repertoire and helping the literacy teachers to build knowledge in the literacy area.

Keywords: Educator formation. Literacy teacher. PNAIC.

Resumen: Este trabajo tiene como objetivo analizar el proceso de formación de instructores (Consejeros de Estudios/OE) que asumen la responsabilidad de instruir a los maestros alfabetizadores y cómo ellos construyen el conocimiento para contribuir en la formación de los maestros alfabetizadores. La investigación es de naturaleza cualitativa y para la colecta de datos, nosotros usamos una encuesta que se contestó por 49 instructores. En la lectura de los datos, entendimos que la formación de instructores todavía es un campo poco estudiado y explorado. Los instructores relatan que la construcción y la movilización de una base de conocimiento necesaria al desarrollo de esa función y, por consiguiente, la construcción del proceso para formar maestros alfabetizadores, (re)constituyendo situaciones que son teóricas y prácticas, movilizando conocimientos referentes al planeamiento, lectura, escritura, oralidad etc. Así, los formadores están agrandando su repertorio de conocimiento y están ayudando a alfabetizadores a construir el conocimiento en el área de la alfabetización.

Palabras clave: La Formación de Formadores. Maestro Alfabetizador. PNAIC.

\section{Introdução}

Nas últimas décadas, acompanhamos vários programas de formação continuada de professores que suscita o lugar do formador de formadores. No Brasil, no âmbito nacional, estadual e local, essa realidade faz-se presente com a finalidade de atender as demandas locais, efetivando programas que têm como finalidade a formação continuada de professores alfabetizadores, como, por exemplo: Programa de Formação de Professores Alfabetizadores (PROFA), Pró-letramento, Gestar, Pacto Nacional de Alfabetização na Idade Certa (PNAIC) etc.; e a melhoria da qualidade do ensino, a aprendizagem e a alfabetização das crianças. Assim, a condição da formação de professores na escola, nas redes municipais de educação e na universidade está sempre em movimento. Um movimento de ir-e-vir que requer uma base de conhecimento e a mobilização de saberes e fazeres para compreender esse processo formativo.

Nesse contexto, este artigo tem como objetivo analisar o processo de formação de professores formadores (Orientadores de Estudos - OE) que, neste 
momento, assumem a responsabilidade da formação de seus pares (professores alfabetizadores), e como esses formadores estão construindo conhecimento para contribuir na formação dos professores alfabetizadores. Para fomentar a discussão, a indagação é: Como o professor Orientador de Estudos do PNAIC vai se constituindo como um professor formador? Os estudos realizados na universidade têm contribuído para a construção desse movimento entre ser professor alfabetizador e professor formador?

Tais questionamentos podem estabelecer bases importantes para sistematizações fundamentais para a formação de formadores. Assim, este artigo está organizado nas seguintes seções: $A$ formação de professores: o desafio da formação; $O$ percurso do trabalbo; o PNAIC; A formação de formadores e $A$ formação dos professores alfabetizadores. Por fim, algumas considerações são elaboradas a partir do que os formadores de professores relataram sobre suas experiências formativas e sobre o contexto local da formação.

\section{A formação de professores: o desafio da formação}

Nos últimos anos, no âmbito internacional (BOLIVAR, 2005; IMBERNÓN, 2012; SHULMAN, 1986, 1987; TARDIF, 2002; VAILLANT; MARCELO, 2001; VAILLANT, 2003) e nacional (ANDRÉ et al., 2013; DINIZ-PEREIRA, 2002; MIZUKAMI, 2006), estudos e pesquisas sobre a formação de professores (inicial e continuada) fazem parte do contexto da escola e da universidade, indicando a necessidade de ampliar a base de conhecimento daquele que se coloca na condição de formador. Talvez esse seja o desafio na e da formação, considerando que há um processo formativo recíproco entre esses atores.

Segundo Imbernón (2012), a formação de professores e do formador de professores, principalmente quando acontece no espaço da universidade, requer um debate sobre a docência como processo contínuo, dinâmico, sendo a formação "[...] um elemento importante de desenvolvimento profissional, mas não é o único e talvez não seja o decisivo" (IMBERNÓN, 2012, p. 97), isso porque, algumas vezes, a formação acontece, mas o desenvolvimento profissional não se concretiza, não efetiva e não contribui para a melhoria do ensino e da aprendizagem. A formação é legitimada quando contribui para o "[...] desenvolvimento profissional do professorado no âmbito trabalhista e de melhoria das aprendizagens profissionais no contexto específico em que se trabalha, já que ajudará a melhorar o ensino e a aprendizagem do alunado, que constitui o objetivo fundamental da docência [...]" (IMBERNÓN, 2012, p. 98). Todavia, esse é um processo que se desenvolve no conjunto, com os colegas, com os gestores, com os alunos e com a comunidade, exigindo uma reconceitualização de conceitos no campo teórico, prático, metodológico e na socialização das experiências. Ainda, para Imbernón (2012, p. 109), 
[...] uma formação deve propor um processo que capacite o professorado em conhecimentos, habilidades e atitudes para desenvolver profissionais do conhecimento, considerando como eixo fundamental de seu currículo de formação o desenvolvimento de instrumentos intelectuais para facilitar as capacidades de reflexão sobre a própria prática docente, e cuja meta principal é aprender a interpretar, auto-avaliar, compartilhar, compreender e refletir sobre o ensino e a realidade social e profissional.

Consideramos que esse deve ser o movimento da formação para formadores e professores, visto que são atores em formação. Assim, os processos de aprender sobre como ensinar e aprender a ser professor (KNOWLES; COLE; PRESSWOOD, 1994) acontecem simultaneamente e devem proporcionar a mobilização dos saberes e dos fazeres para a construção e reconceitualização de novos saberes e fazeres. Não tratamos aqui da formação apenas didática, e sim do que Giroux (1997) vem chamando de formação intelectual do professor para transformar pessoas e situações (SILVA, 2005).

Para Tardif (2002), os professores possuem saberes plurais, homogêneos, sociais, culturais etc., para desenvolver uma formação crítica, reflexiva, autoformativa e que possa garantir a efetivação da aprendizagem. Entretanto, o conhecimento didático é importante nesse processo formativo, e, na prática, representa uma base de conhecimento que é central no trabalho dos professores e dos formadores. É um conceito significativo e ajuda os formadores a centrar-se no que os professores devem conhecer e como podem aprender (MARKS, 1990 apud BOLIVAR, 2005) para desenvolver funções de formador de professores e, especialmente, de professores alfabetizadores. Ainda, vale conhecer as especificidades da área de conhecimento e sua configuração no modo de ver e entender o currículo: objetivos, estratégias e tarefas didáticas, modos de ver e de fazer (BOLIVAR, 2005).

Para tal condição, é preciso defender a garantia e a condição de produção de conhecimentos na formação de professores alfabetizadores. Assim, o professor não pode ser apenas um consumidor passivo de conhecimentos (ESTEBAN; ZACCUR, 2002), aquele que participa da formação e apropria-se daquele conhecimento adquirido como verdade única, não conseguindo contextualizá-lo a partir do local/escola-universidade em que trabalha, dos alunos e da comunidade.

No processo formativo, "a prática é o ponto de partida" (ESTEBAN; ZACCUR, 2002, p. 21), mas, para que esse processo seja dinâmico, “[...] não se trata de descartar a necessidade de aprofundamento teórico, mas, ao contrário, dar ao aprofundamento teórico o sentido de buscas de respostas, que se abrem a novas perguntas num movimento que não encontra um ponto terminal" (ESTEBAN; ZACCUR, 2002, p. 15). É a possibilidade de desvelação constante da realidade multifacetada. 
Nosso desafio é compreender que formadores são os profissionais que estão envolvidos nos processos formativos de aprendizagem da docência de outros professores. É “ “[...] um processo continuado de autoformação - envolvendo dimensões individuais, coletivas e organizacionais - desenvolvido em contextos e momentos diversificados e em diferentes comunidades de aprendizagem constituídas por outros formadores" (MIZUKAMI, 2006, p. 3). Assim, o formador, ao vivenciar os processos de aprendizagem da docência de professores alfabetizadores, está proporcionando condições para seu próprio desenvolvimento profissional embora a formação do formador ainda seja um processo sem muitas explicações e não muito explorado nas pesquisas (VAILLANT; MARCELO, 2001). Algumas características são definidas para o formador de professores, tais como:

[...] aperfeiçoar os conhecimentos e habilidades dos professores mal capacitados; fornecer conhecimentos especializados em matérias que se diagnosticam claras deficiências; facilitar a introdução de reformas educativas, de inovações ao currículo e de novas técnicas ou novos textos de estudo. (VAILLANT, 2003, p. 10-11).

Para atender as referidas características, as pesquisas e os estudos sobre o professor formador tornam-se centrais, principalmente quando o contexto da formação está envolvido com reformas e programas que fomentam a melhoria da formação, do ensino e da aprendizagem de alunos, de professores e de formadores. Tal condição indica "[...] uma redefinição da profissão docente, e consequentemente, dos modelos formativos" (ANDRÉ et al., 2013, p. 20). Assim, podemos retomar o modelo de formação ${ }^{1}$ presente na formação inicial e, também, continuada, indicando que a condição do formador de formadores/professores acontece em uma "[...] situação de trabalho com outros (alunos, colegas, pais, etc.), um saber ancorado numa tarefa complexa (ensinar), situado num espaço de trabalho (a sala de aula, a escola), enraizada numa instituição e numa sociedade" (TARDIF, 2002, p. 15). Nesse caso, a discussão, aqui apresentada, refere-se à formação do professor alfabetizador que já possui experiência docente e deve ter no seu repertório de conhecimentos

[...] formação científica e didática, conhecer as principais linhas de aprendizado que as sustentam, estar apto a trabalhar com adultos e, finalmente, preparado para ajudar os docentes a realizar mudanças comportamental, conceitual e metodológica hoje exigidas pelo sistema educativo. (VAILLANT, 2003, p. 12).

A aprendizagem, a formação e a experiência são conceitos que estão inter-relacionados, mas não estão determinados, isto é, pode haver experiência sem a

\footnotetext{
${ }^{1}$ Segundo Diniz-Pereira (2002), os modelos de formação podem ser classificados como: modelo da racionalidade técnica, racionalidade prática e racionalidade crítica.
} 
aprendizagem. Para pensar a formação e a aprendizagem do adulto (o professor), é necessário considerar a experiência direta do trabalho com o adulto, como ponto de partida e como componente que está presente na formação. E, também, a integração entre o lugar para aprender (universidade/escola), bem como o lugar de fazer (escola/sala de aula), tendo em vista que o trabalho profissional é uma instância que se transforma em meio educativo/formativo (VAILLANT; MARCELO, 2001).

Nesse sentido, a tarefa de trabalhar em programa de ação governamental com planos de "[...] inovação, assessoria, planejamento e execução de projetos nas áreas de educação, formal e informal" (VAILLANT; MARCELO, 2001, p. 12) suscita aprendizagem, formação e experiência do sujeito formador para formar o outro. A autora ainda continua a dizer-nos "[...] que o formador deve ser um mediador entre os conhecimentos e as pessoas que devem adquiri-los" (VAILLANT; MARCELO, 2001, p. 22), possuir domínio de técnicas para a realização da atividade docente, o interesse em experimentar materiais novos e interativos e a capacidade de modificar suas práticas pedagógicas nos processos de formação de seus pares.

Segundo Vaillant e Marcelo (2001, p. 32), podemos definir o formador como uma

[...] pessoa que se dedique profissionalmente a formação em seus diferentes níveis e modalidades tal como o planejamos [...]. O formador é um profissional da formação, e como todo profissional, está capacitado e creditado a exercer esta atividade; possui conhecimento teórico e prático, compromisso com sua profissão, capacidade e iniciativa para aprender e inovar em seu âmbito. Também, [...] o profissional, pertence a coletivos profissionais que assumem princípios e valores em relação com os clientes da formação.

Assim, para a autora, o formador é um sujeito da aprendizagem contínua, um mediador de conhecimentos teórico e prático, mostrando coerência entre o discurso e a prática, assumindo os valores que pretende assumir, vivendo o compromisso da profissão da mesma maneira que espera que os professores que estão sendo formados o assumam quando estiverem no lugar de formadores em seus diferentes níveis: Educação Infantil, anos iniciais e finais do Ensino Fundamental, Ensino Médio, Educação de jovens e adultos e o Ensino Superior. A formação de formadores pode ser entendida

[...] como 'um processo contínuo, sistemático e organizado' que [...] abarca toda a carreira do formador. Do ponto de vista do 'aprender a aprender', os formadores passam por diferentes etapas que representam exigências pessoais, profissionais, organizativas, contextuais, psicológicas, etc., específicas e diferenciadas. (VAILLANT, 2003, p. 35, destaques da autora). 
Diante desse contexto, a formação de formadores requer a capacitação profissional para trabalhar com a formação de professores, sendo necessária uma reflexão sobre o processo de construção e formação do professor formador/alfabetizador que está imerso no contexto de um programa implantado por meio de uma ação do governo federal para atender aos municípios de todas as regiões do país com a finalidade de elevar a alfabetização das crianças - Pacto Nacional de Alfabetização na Idade Certa (PNAIC).

\section{O percurso do trabalho}

A pesquisa realizada possui uma abordagem qualitativa, por compreender como os professores/formadores pensam e estão encaminhando seu processo formativo para formação de professores alfabetizadores em diferentes municípios do sul da Bahia e que fazem parte da região de abrangência da Universidade Estadual de Santa Cruz (UESC). Assim, no envolvimento com os professores formadores na universidade - espaço da formação -, foi planejado um momento para que estes expressassem seu pensamento e aprendizagens em relação a sua condição de formador do PNAIC.

Segundo Bogdan e Biklen (1994, p. 49), uma pesquisa qualitativa indica que o objeto de estudo "[...] seja examinado como a idéia de que nada é trivial, que tudo tem potencial para constituir uma pista que nos permita estabelecer uma compreensão mais esclarecedora do nosso objeto de estudo". Dessa forma, uma tentativa de apreender as diferentes maneiras como os professores formadores estão lidando com o programa, sua formação e a ação de formar o professor alfabetizador.

Trabalhamos com professores/formadores de 23 municípios $^{2}$ do estado da Bahia que, neste momento, assumem a função de Orientadores de Estudos $(\mathrm{OE})$ nos seus locais de trabalho para formar os professores alfabetizadores. Para este trabalho, 49 professores (OE) responderam a um questionário, conforme a tabela 1. Os professores foram identificados como P1, P2, P3 etc.

Tabela 1 - Identificação dos sujeitos

\begin{tabular}{c|c|c|c|c|c}
\hline \multicolumn{3}{c|}{ Sexo } & \multicolumn{3}{c}{ Experiência docente / alfabetizador(a) antes do PNAIC } \\
\hline $\mathrm{M}$ & $\mathrm{F}$ & $\mathrm{NR}^{*}$ & $\mathrm{Sim}$ & Não & NR \\
\hline 1 & 46 & 2 & 33 & 13 & 3 \\
\hline
\end{tabular}

Fonte: Elaborada pelas autoras a partir do material da pesquisa (2013/2014).

Nota: *NR: Não revelado

\footnotetext{
${ }^{2}$ Municípios participantes do PNAIC: Almadina, Arataca, Barro Preto, Camacã, Camamu, Canavieiras, Coaraci, Floresta Azul, Ibicaraí, Ibirapitanga, Itabuna, Itacaré, Itaju do Colônia, Itajuipe, Itapé, Itapitanga, Ituberá, Jussari, Mascote, Santa Luzia, São José da Vitória, Una, Uruçuca.
} 
Para discussão dos dados, elegemos como categorias de análise o programa PNAIC, a formação do formador e a formação do professor alfabetizador.

\section{O PNAIC}

O PNAIC foi instituído pelo Governo Federal, por meio da Portaria 867 de 4 de julho de 2012 (BRASIL, 2012a), a qual define a parceria com estados e municípios que reafirmaram e ampliaram os compromissos previstos no Decreto 6.094/2007 (Compromisso Todos pela Educação), especificamente no tocante ao inciso II do art. $2^{\circ}$ - "[...] alfabetizar as crianças até, no máximo, os oito anos de idade, aferindo os resultados por exame periódico específico" (BRASIL, 2012a) -, que passa a abranger: alfabetização em Língua Portuguesa e em Matemática; realização de avaliações anuais universais, pelo INEP, para os concluintes do $2^{\circ}$ e do $3^{\circ}$ ano do Ensino Fundamental; apoio gerencial, no caso dos estados, aos municípios que tenham aderido ao PNAIC, para sua efetiva implementação e organização de uma rede de aprendizagem.

A Portaria estabelece quem serão os atores sociais que trabalharão no Pacto e suas atribuições. Entre os vários profissionais envolvidos, trazemos para este texto os Orientadores de Estudos (OE), professores do quadro permanente das Redes Municipais de Ensino, com curso de licenciatura, que tenham experiência como coordenadores pedagógicos ou regentes de turmas de alfabetização com disponibilidade de tempo para realização do trabalho previsto.

Para o desenvolvimento do trabalho, destina-se aos OE uma carga horária de 20 a 40 horas semanais, para que possam participar dos encontros formativos realizados pelas universidades com a seguinte organização: um curso inicial de 40 horas, 4 encontros de 24 horas, um seminário final realizado no município de 8 horas, um seminário final estadual de 16 horas e mais 40 horas de estudos e planejamento para a realização das atividades propostas, totalizando 200 horas. Segundo o Caderno de Apresentação do PNAIC (BRASIL, 2012b), os OE atendem os professores em seus municípios, em dez encontros presenciais mensais de oito horas, totalizando 80 horas distribuídas em oito unidades.

Nos municípios participantes da pesquisa, o trabalho realizado pelos $\mathrm{OE}$ tem as seguintes atribuições: organizar grupos de formação com 25 professores alfabetizadores para estudos teóricos na área de alfabetização e letramento, utilizando os cadernos editados pelo Ministério da Educação (MEC); acompanhar o trabalho com seu grupo de alfabetizadores; eleger situações do dia a dia da alfabetização para complementar a formação anunciada no programa. Os encontros de formação são presenciais e mensais.

A territorialização do PNAIC, no estado da Bahia, foi feita por meio da criação de polos de formação constituídos por municípios próximos, gerenciados 
pelas Universidades Federais. Esses polos contêm os seguintes atores sociais: um supervisor geral (indicado pela Universidade), os professores/formadores (selecionados pelas IES), os coordenadores municipais e orientadores de estudos (indicados pelas Secretarias Municipais da Educação) e os professores/alfabetizadores que estão na docência das classes de alfabetização ou multisseriadas.

$\mathrm{Na}$ Bahia, para operacionalização da formação dos Orientadores de Estudos, as Universidades Federais estabeleceram parcerias com as Universidades Estaduais, e estas assumiram polos de formação próximos de seus campi. A Universidade Estadual de Santa Cruz (UESC), em parceria com a Universidade Federal do Recôncavo Baiano (UFRB), assumiu o trabalho do polo Ilhéus e realiza a formação de 90 OE de 30 municípios da sua área de abrangência.

As reflexões contidas nesse texto nascem a partir da relação de uma das autoras como professora formadora de um grupo de 31 Orientadores de Estudos que, por sua vez, trabalha com um grupo de 25 professores/alfabetizadores. Nessa atividade, duas questões têm-se colocado como instigantes e desafiadoras. Uma delas diz respeito à constituição de professores que estavam na regência e/ou coordenação pedagógica e que, ao assumirem a função de Orientador de Estudos, passam a desempenhar o papel de professor formador, bem como identificar e compreender os saberes que esses professores mobilizam como referência para o exercício desse novo papel, o que nos parece essencial para pensar a formação continuada desses profissionais como também a dos professores alfabetizadores que fazem a formação continuada em seus municípios.

$\mathrm{Na}$ escuta a esses professores, nos encontros de formação realizados na universidade, percebemos que a atividade realizada por eles tem implicado em algumas lutas nos municípios, pois, embora tenham feito a adesão ao Programa, eles não conseguem implementá-lo conforme o proposto na Portaria. Os docentes têm dificuldades em criar, nos municípios, a identidade do Programa no tocante à constituição de um espaço físico para realização das formações, do planejamento e dos estudos necessários. Em alguns casos, mesmo não sendo atribuição dos $\mathrm{OE}$, estes precisam pensar desde o espaço físico até a produção e a reprodução do material complementar.

Com relação ao espaço político pedagógico, as narrativas dos professores trazem a ideia de que o Pacto é visto como o Programa do Governo Federal e não uma ação local que envolve organização política em termo de visibilidade do trabalho para a comunidade, e pedagógica na discussão e redefinição das propostas municipais.

Junto a essa questão, outras se impõem, as quais dizem respeito ao processo de formação desses novos professores/formadores, os quais precisam realizar estudos específicos em relação à alfabetização, ao letramento e, também, à formação 
de professores, ou seja, precisam dar conta do seu processo de formação e da formação do seu grupo de professores.

O Programa foi criado em 2012 e implantado nos municípios em 2013. Está, assim, nascendo, mas já fazendo uma busca em anais de eventos sobre pesquisas, estudos e reflexões realizadas tendo como objeto de estudo o PNAIC, considerando que este pode ser estudado com diferentes olhares: processo de alfabetização (linguagem e matemática), leitura, escrita, prática do professor alfabetizador e políticas públicas. Assim sendo, encontramos os seguintes trabalhos (Tabela 2).

Tabela 2 - O PNAIC em estudos e pesquisas

\begin{tabular}{l|c}
\hline \multicolumn{1}{c|}{ Evento/Anais $^{3}$} & $\begin{array}{c}\text { Quantidade de } \\
\text { trabalhos }\end{array}$ \\
\hline ANPEd (2013) & $\begin{array}{c}1 \text { trabalho } \\
1 \text { minicurso }\end{array}$ \\
\hline 19 COLE (2014) & 21 trabalhos \\
\hline $\begin{array}{l}\text { Congresso Estadual Paulista de Formação de Educadores/ } \\
\text { CEPFE (2014) }\end{array}$ & 4 trabalhos \\
\hline
\end{tabular}

Fonte: Elaborado pelas autoras a partir do material da pesquisa (2013/2014).

Esses trabalhos já expressam o movimento, os estudos e as indagações no que se refere à formação do formador, à formação do professor alfabetizador, à prática do professor, à leitura, à escrita (aos processos de alfabetização e letramento).

\section{A formação de formadores: o PNAIC}

A formação dos formadores (OE) acontece na UESC - espaço que deve ser para a reflexão sobre a docência como continuum, dinâmica, contribuindo para o desenvolvimento profissional do professor formador (IMBERNÓN, 2012).

Com base nas respostas dos $\mathrm{OE}$ nos questionários, notamos que estes fazem parte do PNAIC a partir de convite dos responsáveis pela educação em seus municípios, contrariando, assim, o preconizado no Art. 10 da Portaria $\mathrm{N}^{\circ}$ 1.458, de 14 de dezembro de 2012 (BRASIL, 2012c), que estabelece critérios para a seleção dos OE. Em alguns municípios, foram indicados professores que não tinham experiência docente na alfabetização, como ilustra a tabela 1 , o qual indica que 13 Orientadores de Estudos não tinham experiência docente em classes de alfabetização e que, naquele momento, estavam assumindo a função de formar professores alfabetizadores. Vejamos algumas respostas:

\footnotetext{
${ }^{3}$ Nos anais da ANPED, fizemos a pesquisa no GT 10 - Alfabetização, leitura e escrita (www.anped.org.br), 2013; nos anais do COLE, o levantamento foi feito em todas as sessões (anais de resumo impresso) 2014; e, no CEPFE, no eixo 03 - Formação do professor alfabetizador (anais digital - pendrive) 2014.
} 
No primeiro momento resisti, mas após um tempo de reflexão, aceitei como um desafio novo, uma nova experiência positiva para minha vida pessoal e profissional. (P30).

Ao ser convidada pelo município para participar do programa como orientadora, fiquei bastante assustada e aflita pois era algo novo e sempre o novo é algo importante, porém senti-me desafiada e logo então aceitei o desafio. (P33).

Ansiosa e confusa por ser uma atividade/proposta nova, fora da minha realidade, porém disposta a aceitar o novo desafio. Sinto a necessidade de buscar, pesquisar e refletir sobre a minha formação inicial para fortalecer a minha participação. (P16).

Esses excertos representam o pensamento dos $\mathrm{OE}$ em relação à nova função que passaram a assumir, colocando como desafio e como ponto de questionamento a sua formação inicial. Pensamentos de profissionais que, até então, não tinham experiência docente em classes de alfabetização, os quais estavam vivenciando um novo momento de sua formação e de seu desenvolvimento profissional, na condição de "aprender a aprender", passando por novas etapas formativas, as quais possuem exigências que são pessoais, profissionais, contextuais, psicológicas e diferenciadas (VAILLANT, 2003). O contexto mostra-nos que nem todos os municípios cumpriram a exigência em relação ao $\mathrm{OE}$ e a sua experiência docente em classe de alfabetização (BRASIL, 2012c).

Enquanto isso, professores que já tinham experiência na alfabetização também se encontravam no mesmo desafio:

De princípio assustada, depois encantada com todo o conhecimento novo adquirido com os módulos e com a interação com o grupo. (P38).

Me senti diante de um novo desafio onde teria a oportunidade de orientar e de me formar enquanto sujeito e profissional que atua na educação há mais de duas décadas, e buscar a renovação para me adequar a um novo conceito. (P40).

O convite para participar do PNAIC me deixou um pouco preocupada, pois tratava-se de uma nova realidade, mas tinha certeza que era possível realizar um bom trabalho. (P34).

Notamos que tanto os OE com experiência docente em classes de alfabetizadores quanto àqueles que não tinham a referida experiência indicaram o desafio, a preocupação e a nova realidade como condição para desenvolver a função e, também, uma possibilidade de desenvolvimento profissional. Segundo estudos já realizados, o formador de professor é um ator social que irá desenvolver uma função que exige uma base de conhecimento científica e didática e experiência docente (VAILLANT, 2003). Entretanto, encontramos, na nossa realidade, situação diferente. A autora ainda nos diz que "[...] as políticas e reformas educativas 
modernas exigem um docente ideal que, na realidade, não existe" (VAILLANT, 2003, p. 8). Isto é, o Orientador de Estudo no município é o profissional que tem a disponibilidade e o trâmite político com a Secretaria de Educação no momento, visto que foram convidados e indicados. Entre eles, treze não possuem experiência docente em classe de alfabetização.

Para além das questões políticas, parece ser necessário compreender este programa não como um "pacote" que foi encaminhado aos municípios com a finalidade de superar o descompasso no processo de construção da aquisição do sistema de escrita alfabética, mas como uma possibilidade de fortalecer o conhecimento sobre a alfabetização tendo um olhar mais investigativo a respeito dos conceitos e das concepções apresentadas. Nesse sentido, os professores relataram que:

É um programa que veio dar subsídios aos orientadores de estudo com material bem preparado e direcionado para alfabetizar todas as crianças da rede pública até os 8 anos de idade. (P47).

Penso que esse programa abre um leque de possibilidade porque não engessa o fazer pedagógico, mas oportuniza discussões, aprofundamento teórico. Para mim, [a] formação precisa oportunizar a relação real entre prática e teoria e não apenas a sistematização de atividades para cumprir o cronograma. (P2).

Um programa que veio para que nós professores possamos pensar/repensar nossa prática, refletindo sobre o nosso papel enquanto alfabetizador, em um cenário que nossos alunos chegam ao ensino médio sem domínio das necessidades básicas de alfabetização. (P40).

Enquanto política pública, os OE ressaltam a importância do material teórico para estudo referente às concepções sobre alfabetização em um contexto de formação investigativa, crítica e reflexiva. Para os OE, a reflexão teórica vem ajudando a repensar e sistematizar uma base de conhecimento para a alfabetização que vá além do cumprimento de tarefas e de cronogramas de um programa, tendo sempre como referência a situação do seu município/escola/sala de aula, como local da efetivação das ações de alfabetização e a universidade como o local de formação. Nessa condição, não devem ser consumidores desse material (ESTEBAN; ZACCUR, 2002), visto que o formador é um sujeito da aprendizagem contínua, mediador de conhecimentos teórico e prático e não apenas um sistematizador de atividades, tendo coerência entre o discurso e a prática e assumindo o compromisso da profissão da mesma maneira que espera que os professores alfabetizadores que estão sendo formados o assumam (VAILLANT; MARCELO, 2001). Um compromisso político e social que envolve os formadores e os professores.

Em relação à universidade, como espaço formativo, os professores pensam que é o local: 
[...] de formação docente, que possibilita ao professor reconstruir o seu fazer pedagógico enquanto orientadora de estudo, que forma e se forma na medida que se transforma enquanto sujeito mediador de um programa que desempenha um importante papel em nível de alfabetizar. (P40).

Possibilita um estudo mais aprofundado sobre as temáticas que envolvem o processo de alfabetização. (P25).

Um leque de informações, com capacitações que contempla os estudos dos módulos, os seminários e o acompanhamento dos trabalhos no município através do caderno de registro e dos relatórios de acompanhamento. (P35).

Os OE buscam na universidade o desenvolvimento do seu processo formativo para aprofundamento e ampliação da base de conhecimentos, em especial, sobre a alfabetização, o que requer uma dimensão que envolve os conceitos da alfabetização no contexto do currículo: os objetivos, as estratégias didáticas e os modos de ver e fazer em sala de aula, o que perpassa pela questão teórica, conceitual e metodológica. E também, os OE buscam possibilidades para ajudar os professores alfabetizadores a conhecer seus alunos e assim, construir processos de alfabetização (BOLIVAR, 2005). Sendo mediadores da formação, os $\mathrm{OE}$ ampliam seus conhecimentos e habilidades pedagógicas para fortalecer os professores alfabetizadores no trabalho em sala de aula e inovam com materiais didáticos de leitura e escrita, técnicas, discussões, estudos e a identidade profissional (VAILLANT, 2003).

\section{A formação dos professores alfabetizadores: o PNAIC}

Para a formação dos professores alfabetizadores, o programa institui E, também, os OE buscam possibilidades para ajudar os professores alfabetizadores a conhecer seus alunos e, assim, construir processos de alfabetização (BOLIVAR, 2005). Sendo mediadores da formação, os OE ampliam seus conhecimentos e habilidades pedagógicas para fortalecer os professores alfabetizadores no trabalho em sala de aula e inovam com materiais didáticos de leitura e escrita, técnicas, discussões, estudos e identidade profissional (VAILLANT, 2003). A figura do Orientador Educacional que é o ator que está no município e que irá concretizar a efetivação das ações desse Programa e, para isso, vivencia um processo de formação, autoformação e de heteroformação, visto que muitos já construíram uma trajetória como alfabetizadores(as) e com seus pares. Sobre a formação dos professores alfabetizadores, os docentes relataram que é um momento de:

Aquisição de novos conhecimentos, reflexão sobre a prática pedagógica em sala de aula. (P17).

O programa está possibilitando um repensar em relação à organização do ciclo de alfabetização ${ }^{4}$ tanto em nível de diretrizes quanto de planejamento. E

\footnotetext{
${ }^{4}$ Ciclo de alfabetização é uma das possibilidades de organização do ensino nos anos iniciais, constituído
} 
esse repensar provocou um desequilíbrio saudável, principalmente no que se pensava ser alfabetizar, planejamento. (P18).

Tenho percebido uma mudança de postura profissional mesmo com a resistência de alguns colegas. Isso pode ser percebido a partir das visitas e orientações das turmas. A rotina mais elaborada e planejada [...]. (P16).

A construção de novos conhecimentos bem como a mobilização de conhecimentos enfatizada pelo repensar da prática pedagógica e a mudança de postura são pontos indicados pelos OE como processo, movimento, continuum, confirmando, mais uma vez, que a base de conhecimento para a docência não é fixa. Assim, a formação de professores e do formador de professores requer um debate sobre a docência como processo contínuo e reflexivo, como elemento importante de desenvolvimento profissional, mas não o único e nem o decisivo (IMBERNÓN, 2012). Sobre o processo de alfabetização, os professores centraram as atenções nas questões relacionadas ao fazer, à prática, aos recursos didáticos etc.:

Os textos lidos nos cadernos no PNAIC serviram de sugestões para trabalhar em sala de aula com conteúdos e relatos de experiências. Dicas de literaturas infantis, além de acervo enviado pelo MEC. (P47).

Há uma resposta muito boa de todo esse trabalho que vem sendo feito. Os professores relatam que depois das formações compreenderam melhor determinados "conceitos" e, assim, puderam melhorar suas práticas com seus alunos. (P14).

[...] o processo de alfabetização precisa estabelecer uma ponte com o uso social da escrita. E para garantir tais aprendizagens é preciso compreender a escrita como sistema notacional, aprofundar conhecimentos acerca do processo metacognitivo de consciência e conscientização da construção escrita. (P2).

Parece evidente o movimento da formação baseada em situações da prática e para a prática que é valorizado pelos $\mathrm{OE}$, fazendo-nos refletir sobre a condição do consumidor (ESTABAN; ZACCUR, 2002). Além disso, essas sugestões estão ressignificando a prática em cada contexto e sala de aula e aprofundando os conhecimentos sobre a alfabetização para compreender seu uso social. Assim, a base de conhecimento sobre a alfabetização é importante para a "[...] inserção dos formadores em situações de ensino e aprendizagens em diferentes realidades e contextos escolares" (MIZUKAMI, 2006, p. 9).

Em se tratando da formação, perguntamos aos docentes quais e a origem dos conhecimentos mobilizados da experiência como professores/as para desenvolver a função de OE no PNAIC. Fizemos, assim, o seguinte levantamento, conforme a tabela 3 .

dos três anos iniciais do Ensino Fundamental, visto como um bloco pedagógico ou um ciclo sequencial não passível de interrupção, voltado a ampliar as oportunidades de sistematização e aprofundamento das aprendizagens básicas na área de alfabetização. 
Tabela 3 - Origem dos conhecimentos mobilizados para desenvolver a função de OE

\begin{tabular}{l|c}
\multicolumn{1}{c|}{ Conhecimentos mobilizados } & $\begin{array}{c}\text { Quantidade de } \\
\text { OE }\end{array}$ \\
\hline Curso de Pedagogia (graduação) & 3 \\
\hline Curso - PROFA (formação continuada) & 3 \\
\hline Curso - Pró-letramento (formação continuada) & 6 \\
\hline Estudos sobre a Psicogênese da Língua Escrita & 5 \\
\hline Estudos sobre a análise linguística e fonológica & 6 \\
\hline Estudos e trabalhos com textos (gêneros textuais) & 9 \\
\hline Elaboração de sequência didática & 1 \\
\hline Leitura (estratégias de leitura) & 3 \\
\hline Estudos sobre ludicidade & 3 \\
\hline Estudos sobre o processo de alfabetização (SEA) e letramento & 13 \\
\hline Estudos de pós-graduação e outros cursos de formação continuada & 4 \\
\hline Relações interpessoais & 2 \\
\hline
\end{tabular}

Fonte: Elaborado pelas autoras com o material produzido na pesquisa (2013/2014).

Notamos que a mobilização dos conhecimentos para o desenvolvimento da função de OE é advinda de: a) cursos de formação inicial e continuada tais como: Graduação em Pedagogia, PROFA e Pró-letramento; b) aspectos epistemológicos e conceituais: psicogênese da língua escrita, análise linguística e fonológica e apropriação do sistema de escrita e letramento; e c) aspectos da prática pedagógica: os gêneros textuais, sequência didática, estratégias de leitura e a ludicidade. Isso indica que essa é uma função que, para ser efetivada, requer uma base de conhecimento sólida, mas também flexível que possa oportunizar a construção de experiências tanto para o formador quanto para os professores alfabetizadores, tendo em vista que o "aprender a ensinar" é um processo contínuo e que depende dos sujeitos envolvidos (professor, aluno, gestão) e dos contextos (MIZUKAMI, 2006).

Estudos e trabalhos com textos (gêneros textuais) e sobre o processo de alfabetização (Sistema de Escrita Alfabética) e letramento foram os conhecimentos mobilizados por uma grande parte dos $\mathrm{OE}$, considerando a trajetória profissional e estudos anteriores. Além disso, é o anúncio de um pensamento que foi hegemônico na base de conhecimento necessário ao professor alfabetizador.

Em alguns momentos, uma dos $\mathrm{OE}$ relatou que "precisa estar segura no conteúdo" (P37), precisa ter "novos conhecimentos sobre alfabetização" (P4), mas não revela quais são esses conhecimentos. Para outros, aparecem questões relacionadas ao compromisso, à experiência como alfabetizadores, à alfabetização como processo construído cotidianamente.

Partindo da concepção de que a formação é um processo continuum e a base de conhecimento não é fixa (SHULMAN, 1986, 1987), o mesmo acontece com 
a formação do professor alfabetizador. Sobre tal proposição, perguntamos aos docentes quais os novos conhecimentos que estavam sendo construídos, estando na condição de OE no programa PNAIC. Eles relataram aspectos relacionados aos pressupostos epistemológicos e metodológicos da alfabetização, conforme a tabela 4 .

Tabela 4 - Conhecimentos construídos para desenvolver a função de OE

\begin{tabular}{l|c}
\multicolumn{1}{c|}{ Conhecimentos construídos } & $\begin{array}{c}\text { Quantidade de } \\
\text { OE }\end{array}$ \\
\hline Estudos sobre leitura & 2 \\
\hline $\begin{array}{l}\text { Concepção de alfabetizar na perspectiva do letramento e } \\
\text { alfabetização como sistema notacional }\end{array}$ & 4 \\
\hline Hábito de leitura e a literatura & 2 \\
\hline Presença das tecnologias para alfabetizar & 1 \\
\hline A oralidade como conteúdo para construção do SEA & 1 \\
\hline Ludicidade & 2 \\
\hline Organização do trabalho pedagógico com sequência didática & 3 \\
\hline A prática pedagógica com problematização de situações & 3 \\
\hline Estudos da Psicogênese da língua escrita & 1 \\
\hline Estudos sobre o direito de aprendizagem & 2 \\
\hline A literatura (infantil) & 1 \\
\hline A importância e a elaboração do planejamento & 2 \\
\hline Estudos sobre os gêneros textuais & 1 \\
\hline Currículo na alfabetização & 1 \\
\hline A formação de professores com um processo & 1 \\
\hline Ciclo de alfabetização & 1 \\
\hline
\end{tabular}

Fonte: Elaborado pelas autoras com o material produzido na pesquisa (2013/2014).

Assim, fica evidente que, nesse processo de construção de uma base de conhecimento para e na formação para formar o professor alfabetizador, os $\mathrm{OE}$ estão construindo conhecimentos relacionados a: aprofundamento teórico sobre leitura, psicogênese da língua escrita, oralidade, gêneros textuais, currículo na alfabetização, planejamento e ciclo de alfabetização. Em relação aos aspectos metodológicos, eles enfatizaram o uso das tecnologias, a ludicidade, a sequência didática e a problematização.

Retomando as tabelas 3 (mobilização de conhecimentos ${ }^{5}$ ) e 4 (construção

\footnotetext{
${ }^{5}$ A mobilização de conhecimento é um movimento de integração de conhecimentos no momento da ação em sala de aula para desenvolver as atividades de gestão da classe e gestão da matéria, quando é necessário recorrer a conhecimentos construídos anteriormente para reflexões, produção de novos conhecimentos e a resolução de situações da prática pedagógica. Assim, o professor no seu processo formativo e na prática pedagógica mobiliza conhecimentos constantemente (TARDIF; RAYMOND, 2000). Baseado em estudos da
} 
de conhecimentos), notamos que há um movimento recíproco constante, visto que, para alguns, determinado conhecimento estava sendo mobilizado, mas, para outros, estava sendo construído. Tal fato deve-se a diferença da trajetória profissional de cada profissional e, principalmente, porque, no conjunto dos $\mathrm{OE}$, alguns não tinham experiência com a alfabetização. Segundo os relatos, esse movimento foi saudável e enriquecedor para todos, considerando que aprender a ensinar é um processo em constante movimento e não é fixo.

Além desses aspectos, surgiram questões relacionadas ao compromisso profissional, à condição de mediador e o colocar-se no lugar do outro (P32; P26) como novo conhecimento construído para desenvolver a função de OE. Além disso, a ressignificação da prática (P1; P25), os encontros na universidade e no município e o planejamento como espaço de formação e de construção de novos conhecimentos (P30; P38).

Em relação a alguns pontos destacados sobre os processos formativos do formador, podemos inferir que: a escola e a rede de aprendizagem proposta pelo PNAIC nos municípios são locais de aprendizagem profissional; a formação constitui-se como processo de aprendizagem não linear; a importância dos diversos conhecimentos construídos durante as trajetórias profissionais advindos da formação inicial e da prática pedagógica; a importância da prática pedagógica para a construção de conhecimentos de diferentes naturezas: sobre a teoria, a prática, os alunos, a escola, a rotina da escola etc.; a necessidade de explicar uma base de conhecimento, neste caso, para alfabetização; a força da rede de aprendizagem (MIZUKAMI, 2006; VAILLANT, 2003) nos municípios e sua relação com a universidade; compreender que as aprendizagens não são "passadas" ou "entregues" em forma de pacotes, mas devem ser apropriadas e contextualizadas a partir de cada local/escola/rede de ensino; a rede de aprendizagem como espaço de negociação que envolve os $\mathrm{OE}$ e os professores alfabetizadores, contando ainda com os gestores municipais e professores formadores na universidade. Assim, os formadores (OE), mesmo sendo indicados, devem conhecer o Programa PNAIC para ajudar na construção da rede de aprendizagem no município - embora a construção da rede de aprendizagem nos municípios não foi mencionada pelos atores da nossa pesquisa.

\section{Considerações finais}

Com o envolvimento na leitura dos dados, os $\mathrm{OE}$ relataram que a construção e a mobilização de conhecimentos oferecem indícios de uma base de conhecimento

teoria interacionista, a construção de conhecimento é um movimento permanente e sempre está em desenvolvimento, isto é, novos conhecimentos são construídos na troca entre sujeito/objeto do conhecimento. Um movimento constante de ir e vir. 
que é necessária para o desenvolvimento desta função e, consequentemente, os conhecimentos para formar o professor alfabetizador. Assim, os OE, em seu município, com realidade e contexto diferenciados, estão construindo seu processo formador para formar os professores alfabetizadores. Eles valorizaram o material de estudo distribuído pelo MEC/PNAIC e a formação recebida na universidade, principalmente por aqueles que não tinham experiência com a alfabetização.

A aprendizagem da docência está sendo (re)construída com situações que são teóricas e práticas e na mobilização e na construção de conhecimentos referentes ao planejamento, à leitura, à escrita, à oralidade etc. A função de formador é um “[...] território pouco explicado e menos explorado" (VAILLANT, 2003, p. 28), também em nossa realidade, visto que estão desenvolvendo uma função que é estratégica no cenário da política de alfabetização no país/estado/município na contemporaneidade, como "mundos sociais" (SISKIM, 1994 apud BOLIVAR, 2005, p. 28) que legitimam culturas, identidades e formação social e política. Assim, os formadores estão ampliando seu repertório de conhecimentos e ajudando os professores alfabetizadores a construir conhecimentos na área. Uma tarefa que é dinâmica, social, cultural e política, envolvendo a formação do formador e a formação de professores de alfabetização, bem como uma discussão sobre o programa no âmbito nacional e municipal.

Por fim, encontramos pistas que essa formação vem proporcionando aos $\mathrm{OE}$ e aos professores alfabetizadores conhecimentos sobre a alfabetização e habilidades para desenvolver estratégias e recursos que facilitem a aquisição do sistema da leitura e da escrita, o que pode contribuir para a reflexão sobre a própria prática docente, cuja meta é aprender a interpretar, compartilhar e refletir sobre o ensino e a realidade social, profissional (IMBERNÓN, 2012) e local, considerando que o PNAIC constitui-se como um objeto de estudo e pesquisa emergente (Tabela 2), com categorias diferentes: formação, alfabetização, letramento, leitura, escrita, políticas públicas etc., no campo da construção de novos conhecimentos para a formação, para a aprendizagem, para as políticas de alfabetização e para a prática pedagógica.

\section{Referências}

ANDRÉ, M. E. D. A. de et al. Os saberes docentes e o trabalho do professor formador no contexto das reformas e mudanças do mundo contemporâneo. In: LIMA, I. M. da S.; FRANCO, M. J. do N.; CUNHA, K. S. Reflexões sobre formação de professores e processos de ensino e aprendizagem. Recife: UFPE, 2013. p. 19-41.

BOGDAN, R.; BIKLEN, S. Investigação qualitativa em educação. Uma introdução à teoria e aos métodos. Porto: Porto LDA, 1994.

BOLIVAR, A. Conocimiento didáctico del contenido y didácticas específicas. Revista de currículum y formácion del profesorado, Granada, v. 9, n. 2, p. 1-39, 2005. 
BRASIL. Decreto n ${ }^{\circ}$ 6.094/2007, de 24 de abril de 2007. Dispõe sobre a implementação do plano de metas compromisso Todos pela educação, pela União Federal, em regime de colaboração com municípios, Distrito Federal e estados, e a participação das famílias e da comunidade, mediante programas e ações de assistência técnica e financeira, visando a mobilização social pela melhoria da qualidade da Educação Básica. Diário Oficial da União, Brasília, 25 abr. 2007. Seção 1. p. 5

BRASIL. Portaria no 867, de 4 de julho de 2012. Institui o Pacto Nacional pela Alfabetização na Idade Certa e as ações do Pacto e define suas diretrizes gerais. Diário Oficial da União, Brasília, 5 jul. 2012a. Seção 1.

BRASIL. Secretaria de Educação Básica. Diretoria de Apoio à Gestão Educacional. Pacto nacional pela alfabetização na idade certa: formação do professor alfabetizador. Caderno de apresentação. Brasília: MEC/SEB, 2012b.

BRASIL. Portaria no 1.458 , de 14 de dezembro de 2012. Define categorias e parâmetros para a concessão de bolsas de estudo e pesquisa no âmbito do Pacto Nacional pela Alfabetização na Idade Certa, na forma do art. 2o, inciso I, da Portaria MEC no 867, de 4 de julho de 2012. Diário Oficial da União, Brasília, 18 dez. 2012c. Seção 1, p. 15.

DINIZ-PEREIRA, J. E. A pesquisa dos educadores como estratégia para construção de modelos críticos de formação docente. In: DINIZ-PEREIRA, J. E.; ZEICHNER, K. M. (Orgs.). A pesquisa na formação de professores e no trabalho docente: pesquisas, representações e poder. Belo Horizonte: Autêntica, 2002. p. 11-42.

ESTEBAN, M. T.; ZACCUR, E. A pesquisa como eixo de formação docente. In: ESTEBAN, M. T.; ZACCUR, E. Professora-pesquisadora: uma práxis em construção. Rio de Janeiro: DP\&A, 2002. p. 11-24.

GIROUX, H. Os professores como intelectuais transformadores: rumo a uma pedagogia crítica da aprendizagem. Porto alegre: Artes Médicas, 1997.

IMBERNÓN, F. Inovar o ensino e a aprendizagem na universidade. Tradução de Silvana Cobucci Leite. São Paulo: Cortez, 2012.

KNOWLES, J. G.; COLE, A. L.; PRESSWOOD, C. S. Through preservice teachers' eyes: experiences through narrative and inquiry. New York: McMillan College Publishing Co, 1994.

MIZUKAMI, M. da G. N. Aprendizagem da docência: professores formadores. Revista E-Curriculum, São Paulo, v. 1, n. 1, p. 1-17, dez./jul. 2005-2006.

SHULMAN, L. S. Those who understand: knowledge growth in teaching. Educational Researcher, v. 15, n. 2, p. 4-14, fev. 1986. DOI: 10.3102/0013189X015002004

SHULMAN, L. S. Knowledge and teaching: foundations of a new reform. Harvard Educational Review, v. 57, n. 1, p. 1-21, fev. 1987. DOI: 10.17763/haer.57.1.j463w79r56455411

SILVA, T. T. da. Documentos de identidade. Uma introdução às teorias do currículo. 2. ed. Belo Horizonte: Autêntica, 2005.

TARDIF, M. Saberes docentes \& formação profissional. Rio de Janeiro: Vozes, 2002.

TARDIF, M.; RAYMOND, D. Saberes, tempo e aprendizagem do trabalho no magistério. Educação \& Sociedade, Campinas, v. 21, n. 73, p. 209-244, dez. 2000. DOI: 10.1590 / S0101-73302000000400013 
VAILLANT, D. Formação de professores: estado da prática. Rio de Janeiro: Programa de Promoção da Reforma Educativa na América Latina e Caribe, 2003. (Série PREAL Documentos, ก. 25).

VAILLANT, D.; MARCELO, C. Las tareas del formador. Málaga: Ediciones Aljibe, 2001.

Recebido em 28/10/2014

Aceito em 22/06/2015 